\title{
Emerald và F1000 lập nền tảng khoa học mở cho ngành khoa học xã hội
}

\author{
- sciencevietnam $\approx$ SciComm (1) June 21, 2021
}

ENHANCED BY Google

SSHPA (21-06-2021) — Khi tác giả nộp bài trên Emerald Open Research, các bản thảo và tỉnh trạng xử lý bản thảo sẽ nhanh chóng được tải lên trên trang web. Ngoài ra, quá trình bình duyệt sẽ được minh bạch hoàn toàn, thúc đẩy người bình duyệt đưa ra nhận xét mang tính xây dựng thay vì chỉ là quyết định từ chối hoặc chấp nhận bản thảo.

Điều đáng chú ý là, trước khi hợp tác cùng F1000, Emerald đã có sẵn những tạp chí mở như Applied Economic Analysis và China Political Economy. Tuy nhiên, những tạp chí này vẫn chưa sử dụng cơ chế khoa học mở hoàn toàn. Như vậy, việc Emerald lập nên Emerald Open Research, một nền tảng khoa học gần như hoàn toàn mở, là sự cam kết của nhà xuất bản ở mức cao hơn với khoa học mở.

Sự hợp tác trên cũng gợi ý những thiếu xót về công nghệ của những nhà xuất bản khoa học như Emerald trong quá trình chuyển hoá sang mô hình hoàn toàn mở. Để có được nền tảng tốt có thể xử lý và lưu trữ bản thảo và dữ liệu liên quan, thậm chí cho phép người đọc xem và trích dẫn ngay thời điểm xuất bản bản thảo chưa được bình duyệt không phải điều dễ dàng. Vì vậy, những nhà xuất bản vừa và nhỏ như Emerald cần sự hợp tác của F1000, nơi tiên phong về nền tảng công nghệ hỗ trợ khoa học mở.

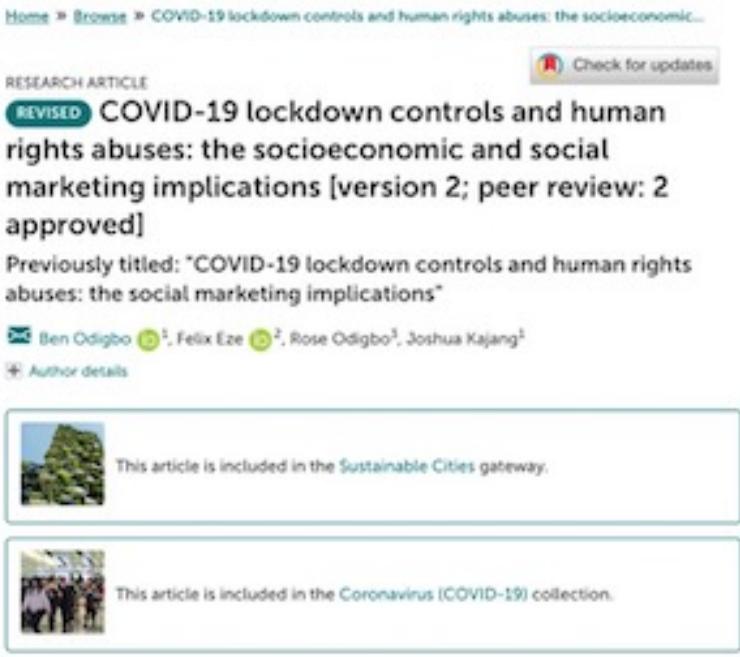

Abstract

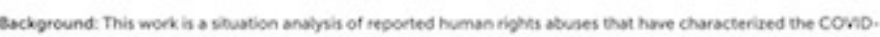
19 controls and lockdown in some countries of the world. This is as documpented by reliable mass media sounces. relevant internutional onganizations and human nights non-povernmental orgavizatiens between January 2020 to Aperia 2020

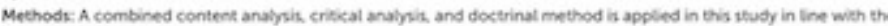
reprobucible resedech process. in is a secondary-cula-based situabion anabsis study, conoucted trough a qualianice reveanch appreach
Open Peer Review

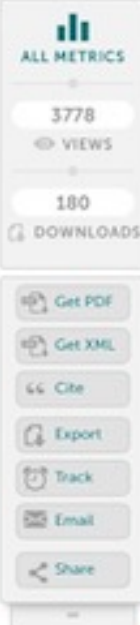

Reviewer Status $\checkmark \checkmark$

Reviewer Reports

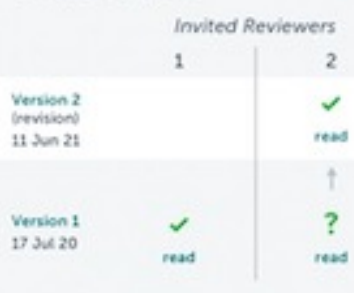

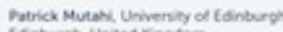

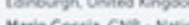

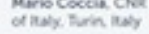

Comments on this article All Comments (1) Add a comment 
Ngoài hạn chế về công nghệ, Emerald Open Research còn gặp những khó khăn khác. Ví dụ, đây vẫn còn là nền tảng non trẻ nên vẫn chưa được biết đến rộng rãi. Dù hệ thống đã bắt đầu tiếp nhận bản thảo từ năm 2018, Emerald Open Research mới chạm tới cột mốc 50 bài vào đầu năm 2021. Vì vậy, nền tảng cần sự hỗ trợ của cộng đồng khoa học ngành khoa học xã hội [3]. Ngoài ra, nền tảng này còn chưa được chỉ mục bởi các hệ thống như Scopus và WoS, nên có thể kẻm hấp dẫn với nhiều nhà nghiên cứu.

Như vậy, dựa trên sự hợp tác của Emerald và F1000, có thể thấy được một số hạn chế trong quá trình phát triển và tiến tới khoa học mở. Hiện nay, theo ghi nhận của SSHPA [4] tính đến tháng 6 năm 2021, vẫn chưa có bài nghiên cứu nào từ Việt Nam được đăng trên đây và số bài đăng trên nền tảng F1000 cũng ít ỏi. Phần nào phản ánh rào cản để tiến tới khoa học mở nơi đây, dù khoa học mở đem lại rất nhiều lợi ích $[5,6]$.

\section{Tài liệu tham khảo}

[1] Emerald Publishing, (2021). Emerald launches a new open research publishing platform - Emerald Open Research - in partnership with F1000.

URL: https://www.emeraldgrouppublishing.com/news-and-press-releases/emeraldlaunches-a-new-open-research-publishing-platform-emerald-open

[2] Odigbo, B., et al. (2021). COVID-19 lockdown controls and human rights abuses: the socioeconomic and social marketing implications [version 2; peer review: 2 approved]. Emerald Open Res, 2:45.

[3] Emerald Publishing, (2021). Emerald Open Research hits 50th milestone. URL: https://www.emeraldgrouppublishing.com/opinion-and-blog/emerald-openresearch-hits-50th-milestone

[4] Vuong, Q. H., et al. (2018). An open database of productivity in Vietnam's social sciences and humanities for public use. Scientific Data 5:180188. URL: https://www.nature.com/articles/sdata2018188.

[5] Vuong, Q. H. (2017). Open data, open review and open dialogue in making social sciences plausible. Nature: Scientific Data Updates. URL: http://blogs.nature.com /scientificdata/2017/12/12/authors-corner-open-data-open-review-and-opendialogue-in-making-social-sciences-plausible)

[6] Vuong, Q. H. (2019). Breaking barriers in publishing demands a proactive attitude. Nature Human Behaviour 3(10):1034. URL: https://www.nature.com/articles /s41562-019-0667-6.

\section{Nguyễn Thanh Thanh Huyền}

(1) Last modified: $6 / 22 / 20213: 24$ PM OViews: 15 ff 0

\section{Bài liên quan:}

- UKRI công bố chính sách xuất bản mở

- Voọc chà vá chân nâu - Một trong những loài khỉ đẹp nhất thế giới

- Tại sao biến thể Delta của virus SARS-CoV-2 lại lan nhanh? 
- Lấy trứng chọi đá: Liệu tạp chí khoa học có bị thay thế bởi preprint?

- Nature sẽ ủng hộ kế hoạch Plan S

Ý kiến bạn đọc (0):

Comment

Gửi bình luận

(C) 2018 - 2021 EASE Vietnam SciComm System. All rights reserved. Powered by Vuong \& Associates.

Built to serve the social sciences and humanities. 